\title{
Aprendizagem Baseada em Problemas como ferramenta para o ensino da Odontopediatria em nível de especialização
}

\author{
Paulini Malfei de Carvalho Costa*; Gloria Fernanda Barbosa de Araújo Castro** \\ * Professora Assistente, Faculdade de Odontologia, Faculdades \\ São José, RJ \\ ** Professora Associada, Departamento de Odontopediatria e \\ Ortodontia, Faculdade de Odontologia, Universidade Federal \\ do Rio de Janeiro \\ Recebido em 12/03/2018. Aprovado em 19/12/2018.
}

\begin{abstract}
RESUMO
O tema abordado neste estudo é o processo educacional na formação do cirurgião-dentista nos tempos atuais. O objetivo do trabalho foi implementar a Aprendizagem Baseada em Problemas (PBL Problem Based Learning) como ferramenta de ensino no curso de especialização em Odontopediatria da Universidade Federal do Rio de Janeiro. A metodologia dividiu-se em duas etapas: a primeira, da elaboração e aplicação do método de ensino, que ocorreu durante o primeiro semestre de 2016, com a carga horária de duas horas semanais, na disciplina Temas em Odontopediatria. A segunda etapa correspondeu à avaliação da ferramenta pelos estudantes, para determinar a percepção dos mesmos quanto ao desenvolvimento do PBL como ferramenta de ensino na formação em Odontopediatria. $\mathrm{O}$ tratamento dos dados foi feito a partir da análise de conteúdo, numa abordagem metodológica qualitativa. Entre os resultados obtidos estão o desenvolvimento do pensamento crítico, maior autonomia, liberdade para questionar e maior participação discente. O reforço do vínculo entre os estudantes também se expressou promovendo uma rede de apoio e dando suporte ao protagonismo, tornando-os sujeitos ativos na construção do seu processo de aprendizagem.

Descritores: Aprendizagem Baseada em Problemas. Ensino. Odontopediatria
\end{abstract}

\section{INTRODUÇÃO}

Mudanças curriculares e pedagógicas têm sido propostas em muitos países, com foco no desenvolvimento do pensamento crítico e em se fazer uma abordagem à formação profissional ligada a uma realidade local específica ${ }^{1}$. Para alcançar esses objetivos estão sendo propostas mudanças político-pedagógicas que envolvem todo o processo de formação do cirurgião-dentista. A Aprendizagem Baseada em Problemas (PBL, Problem Based 
Learning) e a educação com base nas coletividades também são propostas atuais ${ }^{2}$.

Escolas médicas do Reino Unido, Canadá e Holanda, assim como algumas escolas de Medicina no Brasil, como a da UNESP em Botucatu/SP, FAMEMA em Marília/SP e UEL em Londrina/PR, entre outras, adotaram o PBL e a Problematização para ajudar seus estudantes na aquisição de competências essenciais à sua formação ${ }^{3}$. Embora existam cursos de Odontologia utilizando essas metodologias, não encontramos experiências relatadas da utilização do PBL na formação em Odontopediatria em nível de especialização no Brasil.

A Problematização, consolidada por Bordenave e Pereira ${ }^{4}$ em 1982, busca uma inserção crítica na realidade, para dela retirar os elementos que conferirão significado e direção às aprendizagens, e nesse sentido apresenta-se como alternativa metodológica apropriada para cursos nos quais os temas de ensino estejam relacionados com a prestação de serviços à sociedade. Portanto, apresenta-se como uma resposta inovadora frente aos desafios presentes na formação dos profissionais da saúde ${ }^{5}$.

A opção pela educação problematizadora é entendida como uma possibilidade de resolver um problema que todo professor enfrenta diariamente ${ }^{6}$ : como ensinar sem "massificar" ou "coisificar" o estudante? Dessa forma, o melhoramento dos métodos de ensino não deve ser considerado como um fim em si, mas como um meio importante para que a universidade cumpra suas funções sociais.

A educação problematizadora se opõe à educação bancária ${ }^{6}$ quando a primeira reconhece que "uma pessoa só conhece bem algo quando o transforma, transformando-se ela também no processo”. A busca pela solução de problemas implica a participação ativa e o diálogo constante entre estudantes e professores, em uma relação horizontal e dialógica, na qual a aprendizagem é concebida como uma resposta natural do estudante ao desfio da situação problema. A síntese da resposta do estudante tem continuidade na práxis, isto é, na atividade transformadora da realidade ${ }^{6}$.

A implementação do PBL no processo de ensino da especialização em Odontopediatria tem em vista a superação do modelo biomédico centrado na doença como fenômeno individual e da assistência odontológica curativa como foco da formação profissional. Portanto, o objetivo do presente estudo foi implementar a metodologia da problematização como ferramenta de ensino na disciplina teórica do curso de especialização em Odontopediatria da Universidade Federal do Rio de Janeiro (UFRJ).

\section{MÉTODO}

Esse estudo, aprovado pelo comitê de ética em pesquisa, com número CAAE 53577415. 7.0000.5257, configura-se com uma abordagem qualitativa da análise do conteúdo.

O PBL foi implementado no curso de especialização em Odontopediatria da UFRJ durante um semestre letivo, no qual o processo de ensino ocorreu pelo processamento de Relatos de Prática, seguindo o Método do Arco de Charles Maguerez ${ }^{6}$.

Durante o semestre houve 19 encontros semanais do grupo tutorial. Cada estudante produziu 5 relatos de prática e 5 sínteses-resposta ao desafio da situação-problema, totalizando 49 relatos de prática e 49 sínteses individuais que foram discutidas e compartilhadas em grupo. Como trabalho de equipe, os estudantes produziram 5 sínteses do grupo de todo material construído ao longo do semestre e uma apresentação final com todo conteúdo trabalhado.

O método foi avaliado pelos estudantes por meio de um questionário para determinar a percepção dos mesmos quanto ao desenvolvimento do PBL como ferramenta de ensino na formação em Odontopediatria. Os questionários foram identificados em suas falas pela letra "e" (estudante), 
seguida do número cardinal correspondente atribuído aleatoriamente.

O tratamento dos dados foi realizado a partir da análise de conteúdo, na qual o texto é o meio de expressão do sujeito em que o analista busca categorizar as unidades (palavras ou frases) que se repetem, inferindo uma expressão que as representem ${ }^{7}$. Para isto, se fez a categorização, que consiste na classificação dos elementos segundo suas semelhanças e por diferenciação, com posterior reagrupamento, em função de características comuns.

A análise do conteúdo foi a metodologia eleita para esse trabalho, por ser a mais adequada para a análise de fenômenos específicos, compreendendoos mais pelo seu grau de complexidade do que por sua expressão quantitativa. Desta forma, a ênfase não é dada à representatividade numérica, mas à busca de informações suficientes para a construção de um discurso que permita uma análise da subjetividade da questão central do tema pesquisado $^{8}$. A abordagem qualitativa responde às questões dinâmicas e particulares que envolvem uma pesquisa educacional ${ }^{9}$.

\section{RESULTADOS E DISCUSSÃO}

Do grupo tutorial formado pelos estudantes, $80 \%$ desses nunca havia participado de aula ou curso que utilizasse o PBL como ferramenta de ensino. Esse resultado é coerente com o cenário de difusão da metodologia no Brasil ${ }^{10}$. As experiências na graduação da Faculdade de Medicina de Marília/SP e da Universidade Estadual de Londrina/PR, foram pioneiras na utilização da Problematização e do PBL e têm sido referência para outras escolas médicas que buscam um caminho de transformação curricular $^{10}$.

Dentre as características da metodologia consideradas como positivas para o processo de ensino, "discutir temas em grupo" foi a mais citada (39\%). As possibilidades de "desenvolver um pensamento crítico", "ter liberdade de expressão" e "produzir sínteses acadêmicas" também foram relatadas.

Quando, dentre as características positivas, foi solicitado que se destacassem as principais, "aprender a pesquisar" (57\%) e "trabalhar em grupo" (29\%) foram as mais citadas pelos estudantes.

"A possibilidade de trabalhar em grupo e aprender a ser grupo, além de despertar um senso crítico e nos "forçar" a pensar para discutir e elaborar uma situação-problema $e$ respondê-la, aumenta nossa visão $e$ capacitação acadêmica”. (e1)

A aprendizagem em pequenos grupos vem sendo adotada de modo crescente na formação de profissionais na área da saúde, em função dos benefícios trazidos. O pequeno grupo cria condições favoráveis para o processo de ensino, favorece a cooperação e o aprendizado mútuo, estimula o interesse dos estudantes, bem como auxilia no desenvolvimento de habilidades necessárias para o trabalho em equipe. $\mathrm{Na}$ aprendizagem baseada em problemas as atividades se dão no grupo tutorial, que é considerado um componente essencial para o processo, pois é nele que os objetivos de aprendizagem são estabelecidos, o problema é analisado e trabalhado e as relações interpessoais do grupo são construídas.

O grupo tutorial conta com a presença de um professor-tutor, que tem a função de mediar as discussões, estimular e facilitar o processo de aprendizagem e auxiliar na condução de cada atividade. $\mathrm{O}$ professor-tutor utiliza-se essencialmente da apresentação de perguntas, e não de respostas, como nos processos educacionais tradicionais ${ }^{21}$.

"Ouvir a opinião do outro, ausência de certo e errado, reflexão necessária para a confecção da pergunta a ser respondida". (e4)

A formação do profissional crítico e reflexivo é coerente com as premissas propostas pelas 
diretrizes curriculares do MEC, nas quais os egressos do curso de odontologia devem possuir formação generalista, humanista, crítica e reflexiva, para atuar em todos os níveis de atenção à saúde ${ }^{11}$. Portanto, o ensino da odontologia deveria estar consubstanciado em bases humanas e realistas, calcado no paradigma da promoção da saúde bucal. "A metodologia contribui para alunos mais participativos, com maior liberdade para questionar e buscar respostas para suas vivências". (e3)

Esse relato nos leva a reconhecer a importância da contextualização da prática profissional. Pires Filho ${ }^{12}$ afirma que a inadequação entre a formação de cirurgiões-dentistas e as expectativas da sociedade vai além da questão de redefinição de um perfil profissional. Segundo o autor, a solução não está exatamente no perfil do egresso, mas na concepção que se tem a respeito de o que é currículo e do papel que se atribui à escola. Assim, "a escola pode ser pensada como uma mera transmissora de saberes neutros, de valores incontestáveis, sem referência ao seu contexto social, com saberes cristalizados, anteriores à experiência, acima e à parte das relações sociais" $" 12$. Sob esta ótica, a escola não é vista como campo de construção e reelaboração crítica do conhecimento, mas como um local de consumo dos mesmos.

Dentre as razões que justificam a adoção da aprendizagem baseada em problemas ${ }^{13}$, temos algumas características que se manifestam nos profissionais de saúde, como: o conceito de que ao estarem envolvidos no processo, eles têm em si próprios o papel das suas experiência e das suas histórias de vida, que funcionam como uma importante fonte de recursos para eles próprios e para seus pares, e sobre as quais deve ser construída a aprendizagem, assim como a motivação dada à mesma.

"Eu considero positivo para o processo de ensino o momento em que colocamos quais nossas dúvidas sobre o tema e por que queremos estudá-lo”. (e2)

O estudante está mais propenso a aprender quando ele precisa conhecer algo relevante para si e para sua prática profissional ${ }^{13}$, bem como sua capacidade de assumir responsabilidades e tomar decisões, inclusive quanto à identificação de suas necessidades educacionais e a definição de quando e como atendê-las.

"Abranger questões nossas e não somente as pré-determinadas pelo curso". (e1)

"Acho extremamente positiva a possibilidade de levar uma situaçãoproblema para ser discutida $e$ posteriormente realizar uma revisão da literatura sobre o assunto. Não há nada mais didático: exposição da dúvida, discussão e pesquisar para responder a dúvida". (e7)

Sobre quais características da metodologia eram consideradas negativas para o processo de ensino, o "tempo curto para realização das sínteses" foi citado por $67 \%$ dos estudantes, assim como a "ausência de um modelo" para a produção das mesmas foi destacada por $22 \%$ dos estudantes.

"Pouco tempo para realização das atividades e dificuldade para ter liberdade do que falar ou aprender a ter essa liberdade". (e10)

Torna-se fundamental que a ferramenta seja adequadamente inserida em todo projeto de formação, observando seus impactos no cotidiano profissional dos estudantes. Assim, devemos agregar a esse debate o risco de tomar o enfoque problematizador como simples instrumento técnico, desvinculado do projeto político-pedagógico. Discutir o processo educacional a partir do sujeito que aprende, secundarizando as condições concretas de prática e formação, assim como a reconfiguração do papel do educador numa perspectiva dialógica e os dilemas relacionados à reconstrução dos desenhos curriculares são nós críticos que traduzem um desafio para construir propostas formativas em 
saúde. $^{5}$

Ao comparar a Aprendizagem baseada em problemas com a aula tradicional expositiva, $44 \%$ dos estudantes expressaram a possibilidade de "desenvolver pensamento crítico" e $25 \%$ a "liberdade para se expressar e questionar". " $A$ autonomia, pensar "fora da caixa",". (e8)

Nesse sentido vale ressaltar as palavras de Freire $^{14}$ na Pedagogia da autonomia: "ensinar não é transferir conhecimento, mas criar as possibilidades para sua própria produção ou a sua construção", no sentido que para chegar ao conhecimento, educadores e educandos precisam de estímulos que despertem a curiosidade e consequentemente a busca, mas a curiosidade de um não pode inibir a do outro, devem ser complementares para a criação de saberes ${ }^{14}$.

As instituições universitárias brasileiras adotam, em sua maioria, o modelo da pedagogia tradicional. Essa tendência pedagógica ${ }^{15,16}$ centra-se não só na exposição do conhecimento pelo professor e na passividade com que os educandos o recebem, mas na desarticulação existente dos conteúdos e procedimentos relacionados com o cotidiano e a realidade social na qual os estudantes estão inseridos. Sendo assim, torna-se difícil para os estudantes entender a função transformadora dos conhecimentos adquiridos, já que esses são transmitidos para serem apenas absorvidos e memorizados.

"A metodologia permite que o aluno se expresse acerca de um determinado assunto, diferente da aula tradicional; e a discussão em grupo que fazemos sobre determinado tema nos torna seres "mais pensantes", mais críticos com relação às informações recebidas e nos faz pensar além do óbvio" (e4).

Também foi expressa a possibilidade de "maior participação dos estudantes" (19\%) e de "pesquisar diferentes linhas de pensamento" (12\%). "A metodologia nos permite sermos participantes de uma aula e não apenas telespectadores. Sem contar na riqueza de informação adquirida com a troca entre as pessoas do grupo e nas relações interpessoais" (e4).

Nesse enfoque metodológico ${ }^{17}$ cabe ao professor não apenas a transmissão de conhecimentos, mas também o despertar no estudante da consciência crítica e análise dos problemas que o cercam, a fim de construir uma visão ampla, abrangente e integrada da sociedade. Dessa forma, os modelos educacionais que adotam uma metodologia de exposição verbalista, repetitiva, não criativos e sem reflexão crítica devem ser substituídos ${ }^{18}$ por modelos mais dinâmicos e interrelacionados com os problemas e necessidades dos territórios em que as instituições estão sediadas, sendo esse o caminho para o desenvolvimento socioeconômico da sociedade.

Ainda ao comparar a PBL com a aula tradicional expositiva, a possibilidade de "debater dúvidas que surgem nas aulas teóricas" também foi uma característica citada.

"A metodologia da Problematização nos permite debater dúvidas que podem surgir na aula teórica, na qual muitas vezes não temos oportunidade de resposta a essas dúvidas" (e7).

A aula expositiva é conceituada ${ }^{19}$ como uma comunicação verbal estruturada, utilizada pelos professores com o objetivo de transmitir determinados conteúdos aos estudantes. A exposição apresenta algumas limitações, como a ênfase na comunicação verbal, autoritarismo do professor e inibição da participação do estudante.

Sobre o desenvolvimento acadêmico e /ou pessoal do estudante, foi perguntado quais as contribuições da metodologia da problematização nesse processo. Foram citados "escrever o projeto de pesquisa" (20\%), "aprender a questionar e discutir" (20\%), "ter mais autonomia" (20\%), o "fortalecimento das relações interpessoais" (14\%), 
estimular a criatividade (13\%) e "aprender a respeitar diferentes opiniões" (13\%).

"Temos a possibilidade de discutir $e$ perceber diferentes questões, aprendemos a aceitar as informações diferentes, aprendemos como somar". (e1)

Com o exercício do PBL o estudante tem a oportunidade de aprender a construção de um conhecimento compartilhado originado da construção particular de cada sujeito com sua história e experiência de vida, e também compreende que a realidade pode ser observada de diferentes ângulos, com suas características, contradições e diferentes saberes dos sujeitos envolvidos no processo.

O estudante é estimulado a desenvolver o diálogo entre o saber científico e o saber prático, assim como reconhecer a importância do saber dos pacientes na construção do projeto terapêutico, que pode $\operatorname{apontar}^{20}$ para uma reconciliação entre a tecnociência e a vida. Assim, a metodologia contribui no sentido de viabilizar que o estudante busque de forma ampla a resposta para o problema em questão, considerando suas possíveis causas e determinantes, que em geral ultrapassam os aspectos técnico-científicos. "Não se trata de abolir a ciência do âmbito desses regimes, mas de resgatar a dignidade de outros tipos de sabedoria na construção das verdades úteis para a construção da saúde, ${ }^{, 20}$.

No que diz respeito ao desenvolvimento do grupo/ turma, $82 \%$ dos estudantes referiram a "união da turma" como a principal contribuição da metodologia da problematização, seguida por "aprender a debater" (18\%). De acordo com Moran $^{21}$, por meio da Aprendizagem baseada em problemas, " $O$ aluno desenvolve a aprendizagem cooperativa, a pesquisa em grupo, a troca de resultados. A interação bem-sucedida aumenta a aprendizagem".

Experiências e análises teóricas inspiradas nos pressupostos problematizadores precisam ser partilhadas, viabilizando a produção de um conhecimento que fortaleça a mudança ${ }^{22}$, contribuindo para que se possa construir o que se chama de pedagogia da travessia. "Para superar $o$ tradicional é preciso começar tendo a clareza de que o caminho se faz no processo de caminhar" ${ }^{\text {"22 }}$.

\section{CONCLUSÕES}

A Aprendizagem baseada em problemas possibilitou uma nova perspectiva do processo de formação na Odontologia, pois deu relevo ao trabalho em equipe, a autonomia dos estudantes e a busca pela solução de problemas impostos pelo desafio da situação-problema. O ensino crítico e humanizado, a partir das reflexões e do trabalho em equipe, foi valorizado, relacionando-se com todo o contexto das ações e práticas de saúde, ou seja, relacionado às modificações introduzidas por uma intervenção num contexto da vida real, buscando superar a fragmentação e o tecnicismo.

\section{ABSTRACT \\ Problem Based Learning as a teaching tool in Pediatric Dentistry specialization}

The subject of the present study was the current educational process for training dentists. The subject emerged from the need to reorient the teaching process in the Dental Pediatrics Specialization Course of the Federal University of Rio de Janeiro (UFRJ). The study aimed to implement problembased learning as a teaching tool in the Dental Pediatrics Specialization Course of UFRJ. The method was divided into two steps: initially the development and application of the method during the first semester of 2016, with a two-hour a week work load in the Topics on Dental Pediatrics discipline. The second step, the assessment of the tool, used a questionnaire answered by students of the discipline to determine their perception regarding the development of the problem-based learning method as a teaching tool in Dental Pediatrics training. Data were submitted to content analysis, using a qualitative methodological approach. Among results obtained were development of analytical thinking, greater 
autonomy, freedom to question, and more participation of students. Relations among students were also strengthened, promoting a support network and sustaining the empowerment of students, turning them into active participants in the construction of their learning process.

Descriptors: Problem-Based Learning. Teaching. Pediatric Dentistry.

\section{REFERENCIAS}

1. Atchison KA. Community-based clinical dental education: effects of the pipeline program. J Dent Educ. 2009;73(2 Suppl),26982.

2. Mchargkay EJ. The anatomy of a new dental curriculum. Br Dent J. 2008;204:635-8.

3. Berbel NAN. Metodologia da problematização no ensino superior e sua contribuição para o plano da praxis. Semina Ciênc Biol Saúde. 1996;17:130-54.

4. Bordenave J, Pereira A. Estratégias de ensino aprendizagem. 4 ed. Petrópolis, RJ: Vozes, 1982. 25p.

5. Batista N. O enfoque problematizador na formação de profissionais da saúde. Rev Saúde Pública. 2005;39(2),231-7.

6. Bordenave J, Pereira A. Estratégias de ensino aprendizagem. 30 ed. Petrópolis, RJ: Vozes, 2010. p.5-15.

7. Lima MADS. Análise de conteúdo: estudo e aplicação. Rev Logos. 1993; (1):53-8.

8. Minayo MC. O desafio do conhecimento: pesquisa qualitativa em saúde. 4 ed. São Paulo: Hucitec; Rio de Janeiro: Abrasco; 1996.

9. Minayo MC. O desafio do conhecimento: pesquisa qualitativa em saúde. 3 ed. Rio de Janeiro: Abrasco; 1994. p.42.

10. Feuerwerker L. Além do discurso de mudança na educação médica. 1 ed. São Paulo: Hucitec, 2003. p.35.

11. Brasil. Ministério da Educação e do Desporto. MEC/CNE (2001). Processo no: 23001.000318 /2001-75, Parecer no: CNE/CES 1300/01 que trata das Diretrizes Curriculares Nacionais dos cursos de graduação em farmácia e odontologia. Aprovado em 06/11/2001 Ministério da Educação/ Conselho Nacional de Educação, Brasil, 2001.
12. Pires Filho FMA. Construção interativa do saber e do fazer Acadêmicos: O desafio da prática odontológica integral. [dissertação]. Rio de Janeiro: UFF, Niterói, RJ, 1995.

13. Mamede S, Penaforte J. Aprendizagem baseada em problemas: anatomia de uma nova abordagem educacional. Fortaleza: Escola de Saúde Pública. São Paulo: Editora Hucitec, 2008.

14. Freire P. Educação e mudança. Rio de Janeiro, RJ: Editora Paz e Terra; 2001.

15. Luckesi CC. Filosofia da educação. São Paulo, SP: Cortez; 1994.

16. Associação Brasileira de Enfermagem. $7^{\circ}$ Seminário Nacional de Diretrizes para a Educação em Enfermagem no Brasil. Relatório Final. Brasília, DF, 18 a 21 de setembro de 2003. Seção-DF; 2003.

17. Pizzato E, Garbin CAS. O papel do professor no ensino odontológico. Saúde Debate. 2004;28(66):52-7.

18. Dias MAR. Políticas para o ensino superior a partir da conferência de Paris. Univ Socied. 1999;9(18),61-6.

19. Lopes AO. Aula expositiva: superando o tradicional. In: Veiga IPA, organizador. Técnicas de ensino: por que não? 2 ed. Campinas: Papirus, 1993. p.35-113.

20. Ayres JRM. Cuidado: tecnologia ou sabedoria prática? Interface Comunic Saúde Educ. 2015;4(6),117-20.

21. Moran JMA. Educação que desejamos: novos desafios e como chegar lá. São Paulo: Papirus. 2007.

22. Vasconcelos CS. Construção do conhecimento em sala de aula. São Paulo: Libertad, 1995.

\section{Correspondência para:}

Paulini Malfei de Carvalho Costa e-mail: paulinimalfei@gmail.com

Faculdade de Odontologia da UFRJ

R. Prof. Rodolpho Paulo Rocco, 325 - Iltha do Fundão

21941-590 Rio de Janeiro/RJ 